\title{
Design A Suspended Access Equipment Type Elbow JIB With Combination Butterfly Jib Cradle For Bidex Lot VII Building
}

\author{
Nurhidayat ${ }^{1}$, Isdaryanto ${ }^{2}$ \\ \{education.nurh@gmail.com ${ }^{1}$, isdaryantoiskandar@gmail.com ${ }^{2}$ \} \\ Atma Jaya Catholic University of Indonesia ${ }^{1,2}$
}

\begin{abstract}
The Bidex Lot VII building was built in a new commercial area in the CBD BSD, South Tangerang, Banten province. So, tools are needed for the maintenance and repair of the building, precisely in this case it is for the maintenance of the building's facade which must be cleaned regularly and also maintained and repaired if there is a leak on the facade. The problem that occurs because this building has a height of 125 meters will be a problem if in its maintenance there is no tool that is able to reach that height. So, with these conditions the gondola was designed as a means of cleaning and maintaining high-rise buildings. By observing and studying the details of the area that must be cleaned and maintained, the design of the gondola for the building is the "Elbow Jib type Gondola with Butterfly Jib Cradle combination system".
\end{abstract}

Keywords: Gondola building; Elbow type Gondola; Butterfly Jib Cradle; Gondola design; Building maintenance system; Standard EN 1808

\section{Introduction}

\subsection{Gondola}

Currently the development in big cities around the world is very fast, so that many skyscrapers are found with various shapes and different architectural styles, both readymade or in the process of construction and even those that are still in the design which will later be developed. used as an office or residence. To maintain the condition of the building so that it can still be used in accordance with its function, maintenance, repair and cleaning of windows on the outside of the building, roof and canopy are needed. The taller and more complex the shape of the building, the more difficult it will be to maintain it, because of that, tools are needed to maintain the building.

Auxiliary equipment in the building moves to the outside of the building which is directed by the arm (arm / jib), using a steel rope (wire rope) on the lift motor that holds the basket (platform), where the tool is called a gondola. The most suitable gondola for use in the Bidex lot VII building based on a design simulation is the elbow type with a butterfly jib cradle system. Where this type has the advantage that it can bend the jib as desired. 
The elbow type gondola is a gondola by using movements such as arms that can turn right and left, adjusting the amount of the turning radius according to the conditions and needs of the gondola to be installed in the building, maximum rotation can be up to $359^{\circ}$. When doing maintenance and cleaning the ceiling area, with the advantages of the elbow type gondola with butterfly jib cradle, the system for the maintenance of the Bidex lot VII building can be done easily and all desired areas can be reached according to the planning system for building maintenance and cleaning. This gondola has a basket dimension of $2500 \times 600 \times 1000$ with a monocoque aluminum material that can carry a load of $250 \mathrm{~kg}$.

\subsection{Literature Review}

Building cleaning tools in general can be grouped into several types including:

1. Scaffolding

2. Stairs

3. Mobile elevated (boom lift)

4. Rope access system

5. Suspended access system (gondola)

Then in this case, we will discuss the suspended access system (gondola), and if it is classified based on the location of the gondola, it is divided into 2, namely permanent and temporary. Furthermore, the categories based on the location of the engine driving the up and down function are machine gondola on top (Roof power BMU System) and machine gondola in basket (Self power BMU System). Meanwhile, in terms of the movement of the gondola based on the pedestal of its movement, it is divided into:

1. Gondola without using rails (Trackless) where this type uses a steering wheel as its movement direction and for this type the maximum range cannot be more than $10 \mathrm{~m}$, with certain conditions in this case the gondola mast height should not be more than 4 meters.

2. Gondola using rails as guides when the gondola is run on the roof floor and for now the existing ones can be designed up to an arm length of $40 \mathrm{~m}$ but in terms of design calculations can be longer according to needs but must take into account other things such as dead load of the tool, strength structure and price .[3,4]

While based on the model or based on the shape of the gondola, it is divided into:

a. Telescopic (jib, mast, or combination jib and mast)

b. Articulated/luffing

c. Elbow ( standard, $Z$ elbow)

d. Fixed (mast, jib)

Of the various types, based on technical, structural, aesthetic and cost considerations without reducing the function and purpose for cleaning the Bidex lot VII building, it can be decided by using the elbow model with the butterfly jib cradle system.[4]

The method used in planning the gondola design here is to use a simple drawing technique that is only using Autocad, from the picture it is actually possible to review all aspects of the building details, especially the facade details (outer walls of the building) and from the picture you will get how to clean the building. certain positions according to the shape of the building which of course must consider high safety because here it will relate to the height of the building and other factors such as the wind which will affect the operation and safety of the gondola itself, if you are still in doubt then make it in 3 dimensions using the SketchUp program, or use the Solid Work program. [1,2]

In carrying out the planning and design of the Bidex lot VII building, what is taken into consideration is based on the gondola reference from a building that has characteristics that 
have some similarities in architectural models, for example in Indonesia, the Margo city hotelDepok. Gondola is a 4-star hotel that owned by a subsidiary of PT Djarum. which has an Elbow gondola type but has different dimensions.

Furthermore, in this paper we will explain about the Elbow type gondola with butterfly jib cradle based on considerations of function, safety and architectural aesthetics, which are highly highlighted in this Bidex Lot VII Building .

\subsection{Gondola Design Method}

In this design, to clarify ideas and ideas for using the lufing model, we tried to make a simulation using Autocad, and simulated it into SolidWork, these details must be done in planning the gondola, including :

1. The farthest point (outreach from the center of the gondola to the center cradle (basket)

2. The length of the first jib and the length of the second jib at the gondola operational point with the turning radius of the two jibs based on the operational plan of the gondola when in use.

3. The highest point of the gondola (which here must be considered is the height of the parapet from the building)

4. Other ME equipment on the building's rooftop 5. The shape of the building if it is not symmetrical (is there a slope, recess, the amount of angle must be taken into account) in order to know how to clean and safety

5. The points of restraint (safety in the transom of the building must be observed according to the EN 1808) standard with the provisions of a maximum of 40 meters vertically from the ground floor point, then every maximum of 20 meters vertically until the highest point of the wire rope position exits the head of the gondola jib.

Then to find out the action of the reaction moment that will be used to calculate the loading on the building structure is carefully calculated using software from the principal. In addition, in determining technical specifications, we usually adhere to a design and built system, but in practice there are rules that have been set. determined by the consultant and can be given a deviation (tolerance) that is still acceptable.

For detailed technical specifications on the Bidex lot VII building, it was designed based on the provisions issued by PT Sigmatech as the Mechanical Electrical Consultant, then the Structure Consultant by PT Haerte Konsutan Engineering, Architectural Consultant by PT Airmas Asri with Main Contractor by PT Tatamulia Nusantara Indah, and of course with the approval of Construction Management Nusapratama Dwi Kharisma as the owner's representative, namely PT. Asia Propertindo Building, and in general can be described as follows.[1] :

1. The standard used refers to the EN 1808 standard,

2. Can clean all areas of the facade building and from the ground floor to the roof floor

3. The permitted transport capacity is at least $250 \mathrm{~kg}$

4. The overall dead load of the gondola is max 10 ,tons

5. The clearance of the prepared gondola is $2800 \mathrm{~mm}$

6. Using the gondola type with the machine in the basket)

7. The gondola must be able to reach the area behind the closed engine room which the gondola plan cannot pass.

8. The area that protrudes deep from the building (Recess) must be maintained so that the gondola must be able to enter the area as deep as $900 \mathrm{~mm}$ 
9. The use of restraint sockets as a safety device during gondola operations according to the standard must be determined at the points and details according to the EN 1808 standard

From the above, a design that is in accordance with the architect's design, mechanical electrical planning, civil planning, facade planning and of course the price will be approved by the owner of the Bidex lot VII building. Then to determine the balance of the load on the gondola will always use the basis of the balance of forces where the force is equal to the reaction force. This is done to determine the leverage that occurs at the fulcrum of the wheel on the gondola. The flowchart in the design of the gondola is as follows in figure 1:

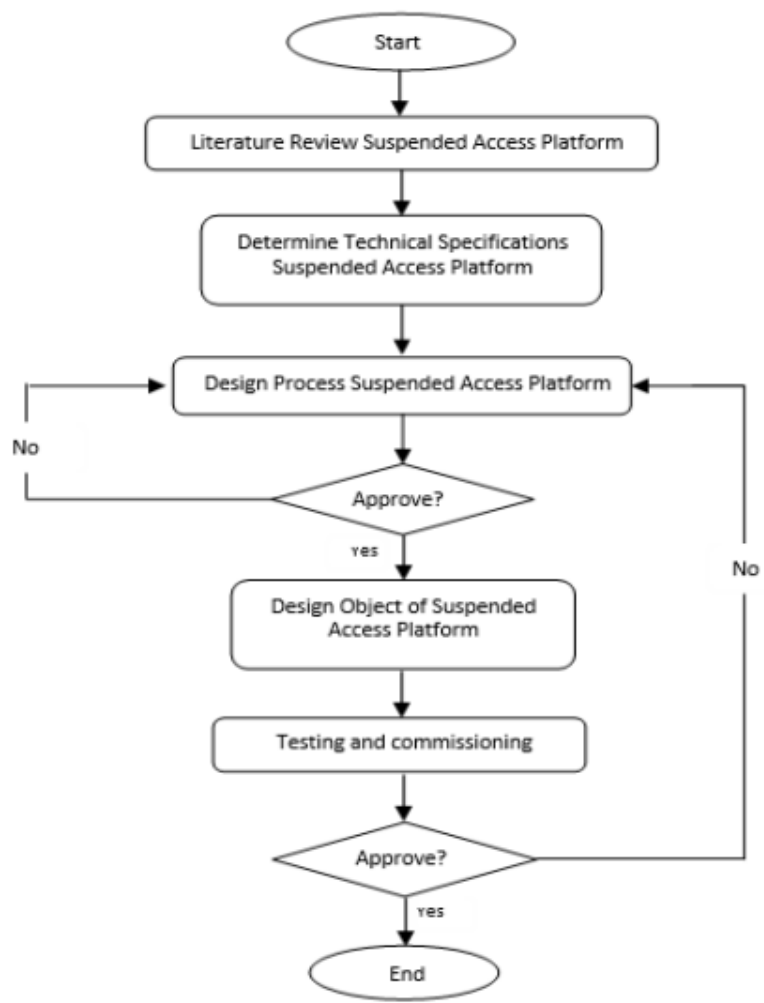

Fig. 1. The design of gondola

From the figure 1, the process will be described from beginning to end, if the process is not accepted by design by the parties related to this project or conformity to the EN 1808:2015 standard then it must be repeated, and if the process is correct then it will be continued and until the testing and commissioning stage, this is where the final assessment of the suspended access platform (Gondola/BMU) design is here. If this part is accepted, then it is finished, but if it has not been accepted, you have to repeat it again.

\subsection{Clarity of Gondola Function}


Things that must be considered in the desired design in the manufacture of the elbow type gondola with the butterfly jib cradle system in the Bidex lot VII building project are based on the form and function design which can be explained as follows:

1. Traversing / traveling movement: is a gondola movement that is needed to shift horizontally (movement to the left or right)

2. Lifting movement: is the up and down movement needed to shift the gondola vertically

3. Elbow movement / rotation on the first jib and the second jib horizontally on the gondola jib where this movement is a movement to bring the gondola basket position closer to or away from the facade area to be cleaned.

4. Slewing head movement: where this movement is a movement to align and bring the position of the gondola basket closer to or away from the facade area to be cleaned.

5. Butterfly jib head which is used to bring the basket closer to the recess position of the building so that it can enter and clean the area, as far as $900 \mathrm{~mm}$ protrudes into the building.

\subsection{To-Do List}

In addition to the part of the gondola above, there are several other parts that will be briefly explained, including the following:

1. Mast or so-called gondola pole whose height follows the height of the crown and also the next floor structure based on architectural design

2. Motor, on the gondola there are 5 function parts that are driven by a motor, namely: a. Motorcycle traveling / traversing b. Lifting motor c. Motor turn table / slewing arm d. Slewing head motor e. Butterfly jib head

3. Jib / arm, must be able to reach all facade areas including the area behind the machine room which is

4. Hoist drum rolling system

5. Wire rope

6. Cradle / basket has a minimum size of $2500 \mathrm{~mm}$ x $630 \mathrm{~mm} \times 1100 \mathrm{~mm}$. In this design, it is expected to meet the desired criteria, namely:

a. Can clean all sides of the facade area

b. Can be used to clean the building fin area from the ground floor to the roof floor

c. From the safety system, operational use can be guaranteed

d. Can carry the desired load of at least $250 \mathrm{~kg}$

\section{Results and Discussion}

Gondola is a machine that is specially designed in every building because the design of the building is always different in model, which will be the object of this design include:

1. Elbow type gondola with track design with butterfly jib cradle system

2. Can clean all façade areas of the building and in no more than 3 months all façade areas

\subsection{Conceptual Design}


Table 1. Alternative solution for design MBU

\begin{tabular}{|c|c|c|c|c|}
\hline No & Sub function & \multicolumn{3}{|c|}{ Alternative solution } \\
\cline { 3 - 5 } & & I & II & III \\
\hline 1 & Cradle type & Butterfly jib & Pantograph & Scissor \\
\hline 2 & Cradle dimension & $\begin{array}{c}2000 \times 1250 \\
\mathrm{x} 1100\end{array}$ & $\begin{array}{c}2500 \times 1250 \\
\mathrm{x} 1100\end{array}$ & $\begin{array}{c}3000 \mathrm{x} 1250 \\
\mathrm{x} 1100\end{array}$ \\
\hline 3 & Deadweight gondola & 12 ton & 14 ton & 16 ton \\
\hline 4 & Track gauge & 1500 & 2000 & 2500 \\
\hline 5 & Mast and jib materials & BS Sheet & Hollow & Pipe iron \\
\hline 6 & Drum roller position & Cradle & Roof & \\
\hline 7 & Cable control position & Inside wire rope & $\begin{array}{c}\text { Outside } \\
\text { wire rope }\end{array}$ \\
\hline 8 & Counterweight & Concrete and iron & Whole iron & Concrete \\
\hline 9 & Type of track & Use rail & Trackless & \\
\hline
\end{tabular}

The sub-functions $1,2,3,4,5,6,7,8$ and 9 when combined will be combined as a whole so as to produce a concept design for cleaning tools which are commonly called BMU (building maintenance unit) or often known as Gondola. Concept designs that can be compiled from a combination of 1-9 there are many variations, including:

1. Variation $1: 1$ (I) - 2 (I) - 3 (I) - 4 (I) -5 (I) - 6 (I) - 7 (I) -8 (I) -9 (I)

2. Variation $2: 1$ (II) - 2 (II) - 3 (II) - 4 (II) - 5 (II) -6 (II) - 7 (II) -8 (II) -9 (II)

3. Variation $3: 1$ (III) - 2 (III) - 3 (III) - 4 (III) - 5 (III) -6 (III) - 7 (III) - 8 (III) - 9 (III)

4.

5. Variation $\mathrm{n}: 1$ (I) -2 (II) -3 (I) -4 (II) -5 (1) - 6 (2) - 7 (1) -8 (I) -9 (I)

6. And so on

All of these variations can be realized into a conceptual design, but the priority is chosen which is considered the most optimum based on technical and economic considerations. The best variation will be continued as a form design, so that the conceptual design for the gondola here is chosen as variation $\mathrm{n}$ which is a combination of sub-functions:

1. 1 (I) - 2 (II) - 3 (I) - 4 (II) - 5 (1 ) - 6 (2) - 7 (1) - 8 (I) - 9 (I), the technical and economic reasons underlying the variation $\mathrm{n}$ are ; 1 . In this Type Elbow choose the $\mathrm{n}$ variation, with a basket design length of $2500 \mathrm{~mm}$ is able to include 2 glass panels, where the existing panels are 1200 per panel so it will be efficient when using a 2500 basket once down,

2. The weight of this gondola was chosen based on the initial estimate of the total weight of this gondola is 8 tons, of which the maximum limit given by the consultant is 10 tons,

3. This gondola has a rail track inside the parapet following the circumference of the building

4. The position of the roller drum is selected to be on the roof using the lebus groove roller model with the cable inside the wire rope

5. Based on the reasons for choosing the variation $n$, variations: 1 (I) - 2 (II) -3 (I) -4 (II) -5 (1) -6 (2) - 7 (1) -8 (I) -9 (I) then the resulting conceptual design is:

The gondola chosen is the Elbow Type, with a Butterfly jib model basket with dimensions of $2500 \mathrm{~mm} \times 600 \mathrm{~mm} \times 1000 \mathrm{~mm}$ with a weight of \pm 8tons from the gondola, with a distance between rails of $2000 \mathrm{~mm}$, with the material used is black steel sheet type which is shaped with how to roll and the wire rope is rolled up with multilayer rollers on the roof with a gondola movement control cable inside the wire rope which has a tensile break strength of $2900 \mathrm{~kg} /$ wire rope and counterweight is made from a combination of steel and concrete as 
well as for its direction using rails from $\mathrm{H}$ beam $200 \mathrm{~mm}$ x $200 \mathrm{~mm}$ x $8 \mathrm{~mm}$ x $12 \mathrm{~mm}=599 \mathrm{~kg}$ / 12 meter.

\subsection{Gondola Design and Details}

The design of this gondola is an Elbow type with a butterfly jib cradle system which will be used for cleaning the facade of the Bidex lot VII building. The consideration of using this form is based on the function for the entire area to be cleaned, namely the entire building facade, the mechanical-electrical room ceiling and the inner walls of the Bidex lot VII building, and the top floor is not cleaned using a gondola because it is a private area. The design of this gondola uses technical rules according to EN 1808 which contains "safety requirements for suspended access equipment - design calculation, stability criteria, construction - ecxamination and tests", and this design is also based on the aesthetics of the building from the design designer (architect) for aesthetic beauty of the building, as well as considering structural load permitted by the structural planner, namely PT. Haerte engineering consultant.

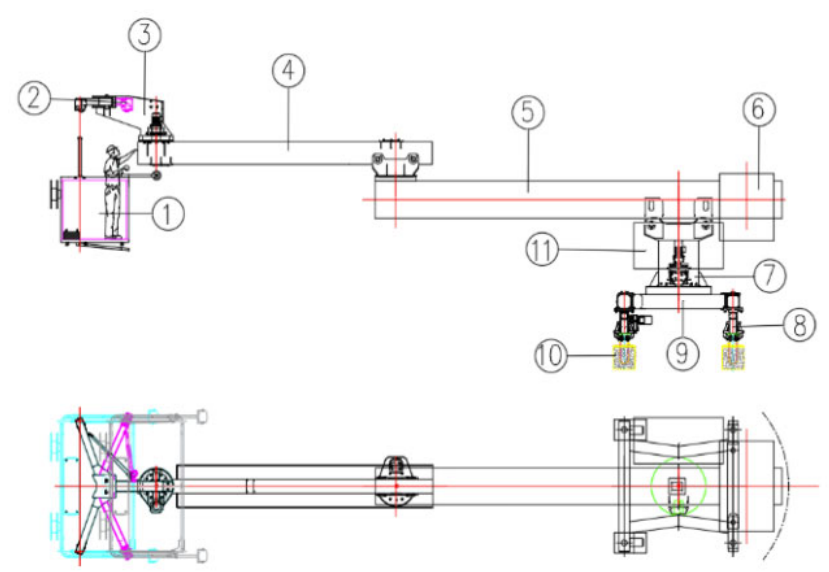

Fig. 2. Gondola Design by Autocad

Caption : 1. Platform/Cradle 2. Butterfly jib system 3. Jib Head 4. Second Jib Elbow 5. First Jib Elbow 6. Counterweight 7. Mast 8. Traversing system 9. H- Model trolley 10. Pedestal 11. Hoist with House machine In a gondola detail design, what a gondola system designer must have is a detailed image of the entire building including a 4-sided view, floor to floor drawings and floor plans. By using Autocad, the gondola designer will make a simulation of the gondola movement and operation by the operator, from this simulation it will be known whether there are difficulties in maneuvering or moving or not, and the most important thing is that it is free from obstacles. Therefore, the design of the gondola for each building will always be different because each building will have its own artistic value and characteristics, unless the building is designed for twins or typical. And in the design for this building in the detailed design of the building according to the Bidex lot VII building project (see figure 3) 


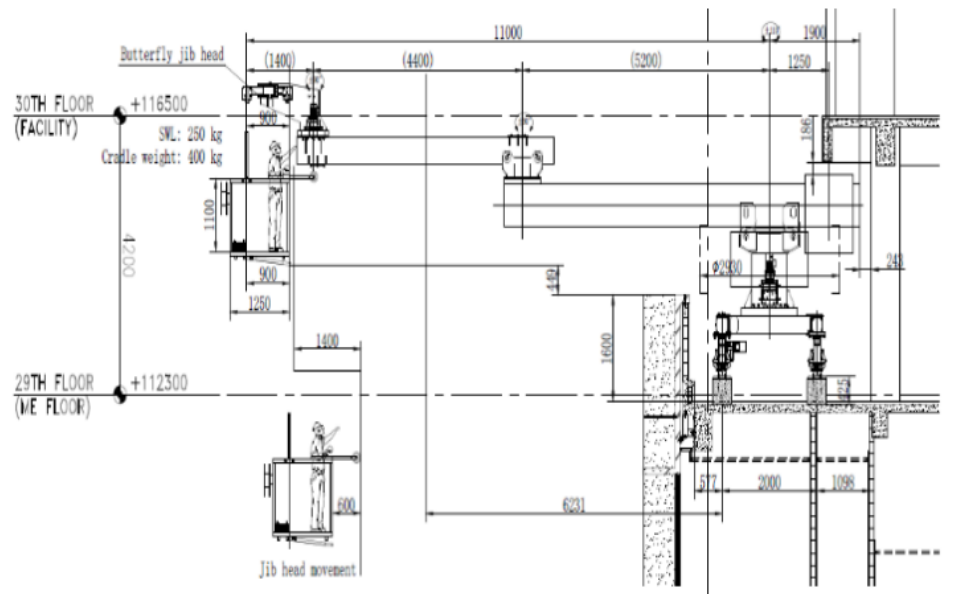

Fig. 3. Detailed Gondola simulation on building sections

\subsection{Gondola track design}

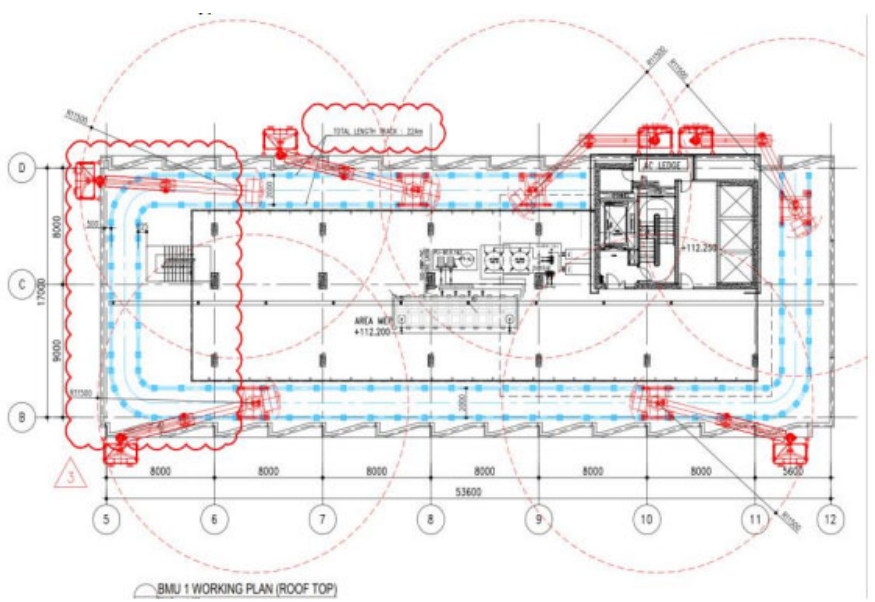

Fig. 4. Design track layout by Gondola

In designing the gondola track, several stages are needed so that in the implementation of the installation there are no errors, especially in the loading of the structure and also the maneuvering of the gondola does not hit part of the building, so the design of the track system is made as shown in the figure 4.

In planning the rail track for the gondola there is a standard calculation based on the results of the analysis of the reaction at the point of the gondola wheel when parking or when operating. From these conditions, the highest compressive force that occurs in the four-wheel load traversing is taken with the following table 2: 
Table 2. Wheel load moment gondola

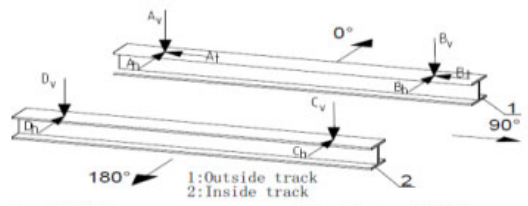

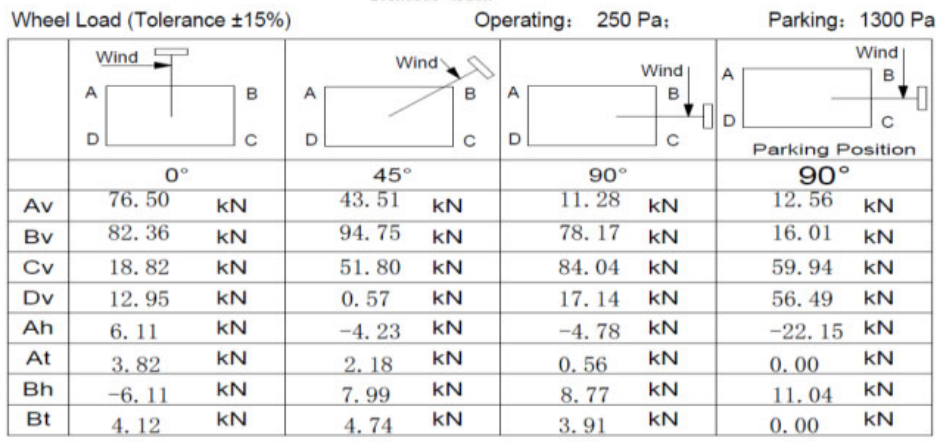

From the design calculations, we see that the largest wheel load occurs in the wheel section B when operating at an angle of $45^{\circ}$, which is $94.75 \mathrm{kN}$. After that we have to calculate the load if it is entered into the calculation of the standard EN 1808: 2015 we get the size of the rail used, namely by using the H-Beam 200, with a specific size of $200 \mathrm{~mm}$ x $200 \mathrm{~mm} \times 8 \mathrm{~mm}$ $\mathrm{x} 12 \mathrm{~mm}=599 \mathrm{~kg} / 12 \mathrm{~m}$, based on the following calculation in the figure 5:

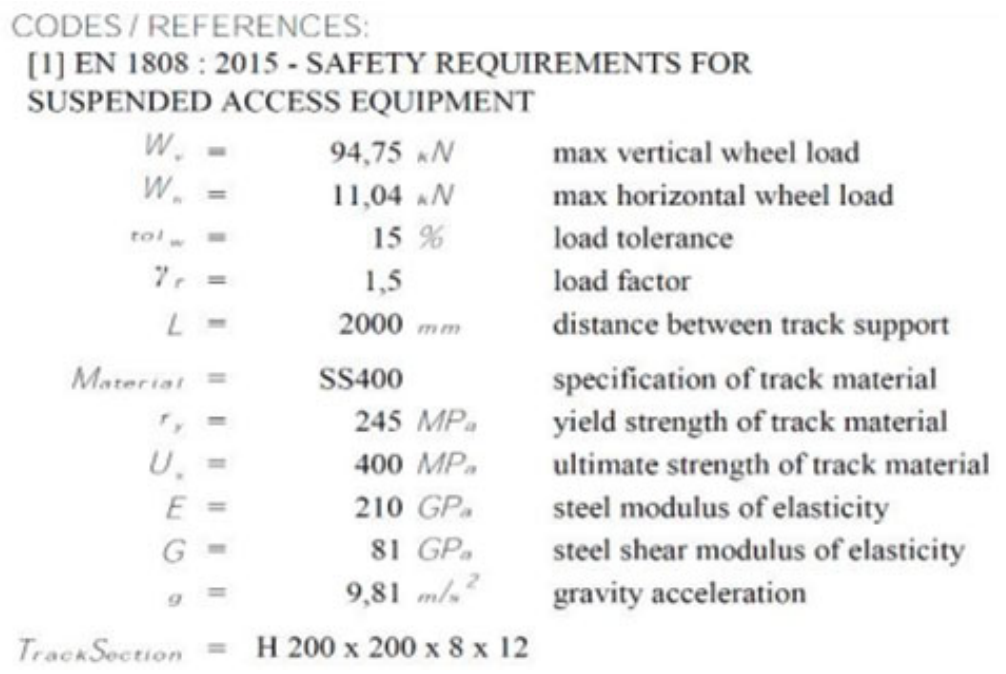




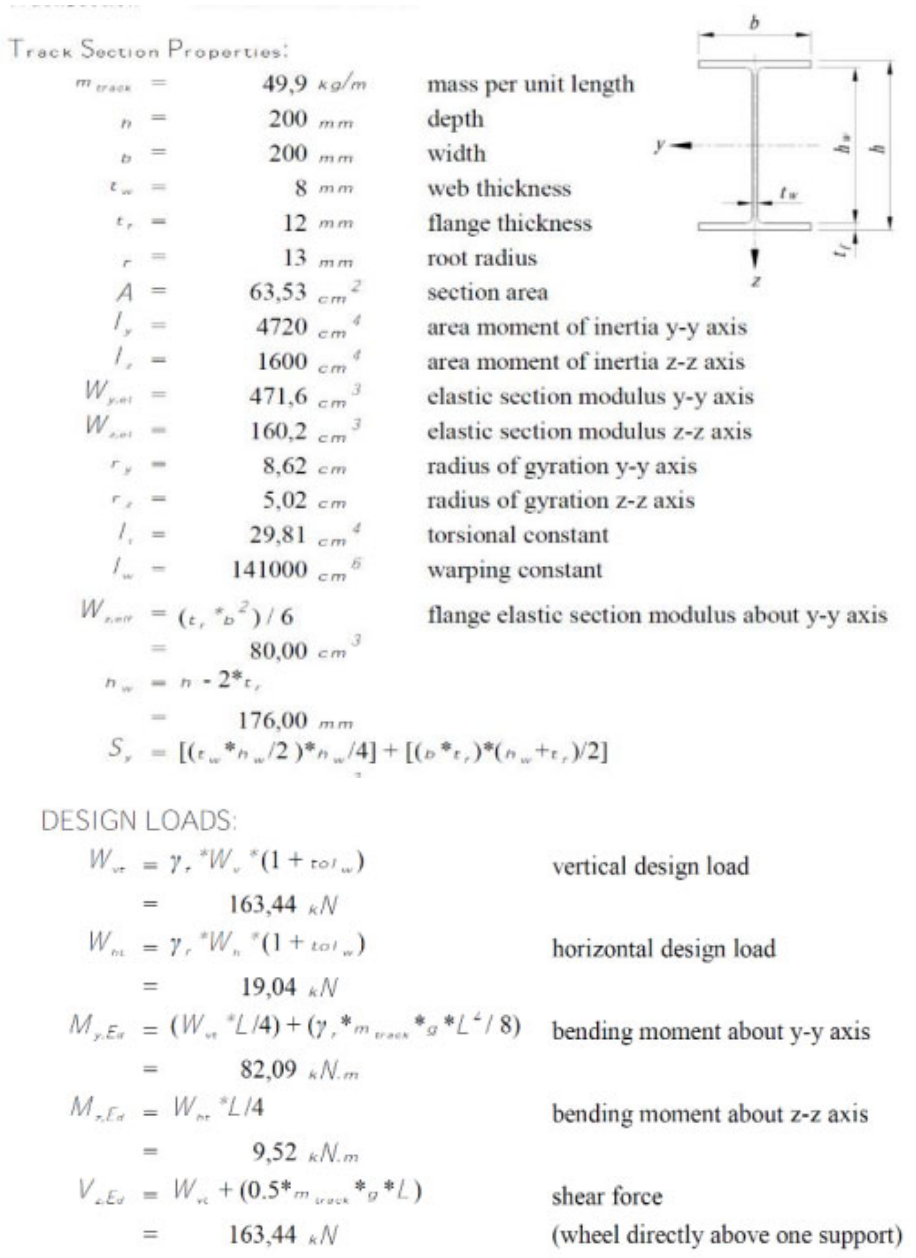

Fig. 5. Design Calculation

From this data, a check is then carried out based on the calculation of the moment against the rail to be used with a value that cannot be $>1$, and the checks include:

a. Buckling check (EN 1808 Annex G.5.4.1)

After entering into the formula

$\boldsymbol{M}_{\boldsymbol{y}, \boldsymbol{E} d} \boldsymbol{d} \boldsymbol{M}_{\boldsymbol{b}, \boldsymbol{R} \boldsymbol{d}}=\mathbf{0 , 7 1}$ the value is which means accepted

b. Check Crippling of under wheel check (EN 1808 Annex G.5.4.3.b)

After entering into the formula

$\boldsymbol{F}_{z, \boldsymbol{E} d} / \boldsymbol{F}_{z, \boldsymbol{R} d}=\mathbf{0 , 5 8}$ the value is which means accepted

c. Check Buckling of web under wheel (EN 1808 Annex G.5.4.3.c)

after entering into the formula, the value is

$\frac{\boldsymbol{F z}, \boldsymbol{E} \boldsymbol{d}}{\boldsymbol{X} * \boldsymbol{N} \boldsymbol{C} \boldsymbol{R d}}=\mathbf{0}, \mathbf{6 4}$ which means accepted.

d. Check Deflection (per BS 5950-1 for overhead crane girder) 
after entering into the formula, the value is

$\delta_{\max } / \delta_{a}=\mathbf{0 , 5 5}$ which means accepted

\subsection{Details of Design Cradle}

Based on the request for technical specifications issued by the mechanical-electrical consultant, the gondola basket must be made of aluminum, and we design using an aluminum monocogue with a length of $2500 \mathrm{~mm}$, a width of $1250 \mathrm{~mm}$, and a height of $1100 \mathrm{~mm}$ and this basket is designed to withstand a minimum load. $250 \mathrm{~kg}$, and the bumper is made in front of the basket to absorb impact in the event of a swing, so as not to cause damage to the aluminum facade frame or building glass. While the cradle model used is the butterfly jib because of the special design for buildings that have a large recess area or part protruding into the facade with a depth of between $500-1000 \mathrm{~mm}$, the butterfly jib cradle was chosen to be optimal. and with the butterfly cradle system, this greatly impacts the effectiveness of the gondola operation at a rational price, although in this design it will increase the overall load of the gondola which is quite significant, but the advantages of this system in terms of price and operation are better.

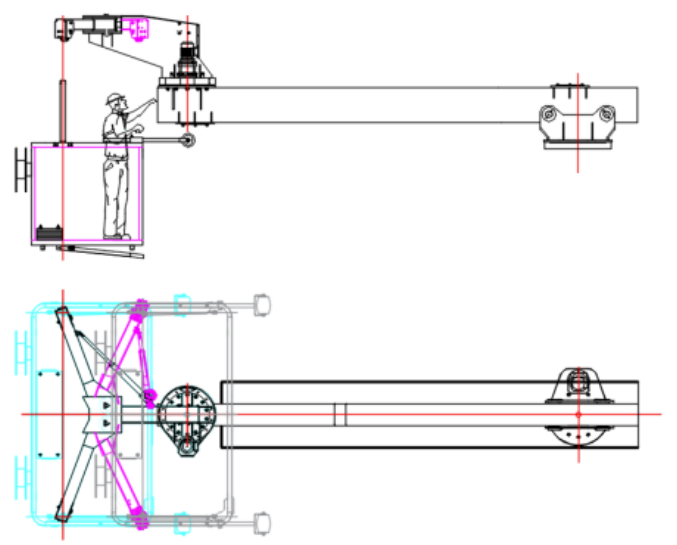

Fig. 6. Detail of design butterfly cradle of BMU

\subsection{Restrain Socket}

In this case the design will be adapted to the standard, EN 1808 version 2015 (european standard) as shown in figure 7 . So, in the design of the safety system so that accidents do not occur during operation, a safety device called Restraint Socket is made which is equipped with a softrope system where for images and horizontal distances are made per 2 façade panels \pm 3 meters. Based on the standard EN 1808: 2015, that vertically the maximum distance between the restraint sockets is 20 meters, where the determination of the first point of restraint is measured from the exit of the wirerope (roller head) to the part of the facade structure (transom/mullion/other) that is able to withstand the minimum load is $2.7 \mathrm{kN}$. Then the next 20 meters, and continue until the lowest point in the restrain position with a maximum distance of 40 meters from the ground floor and for the detail vertical distance position in figure 8 as follows:[1] 


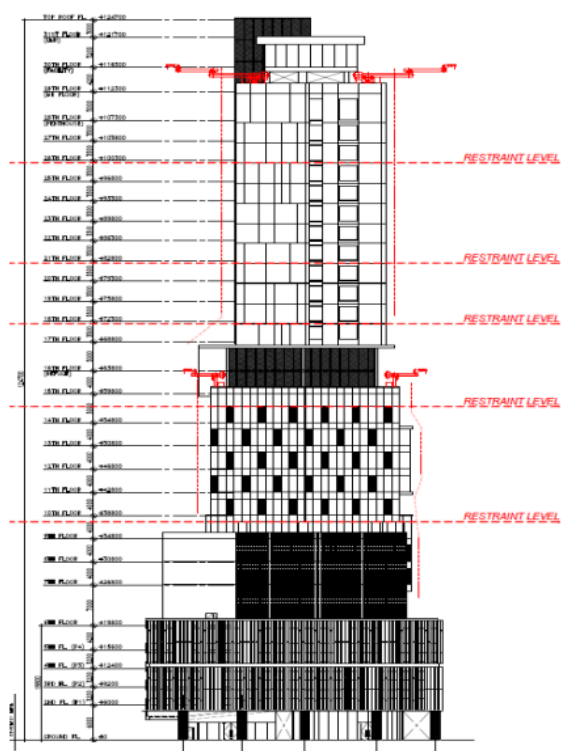

Fig. 7. Vertical elevation restraint position refers to standard EN 1808;2015
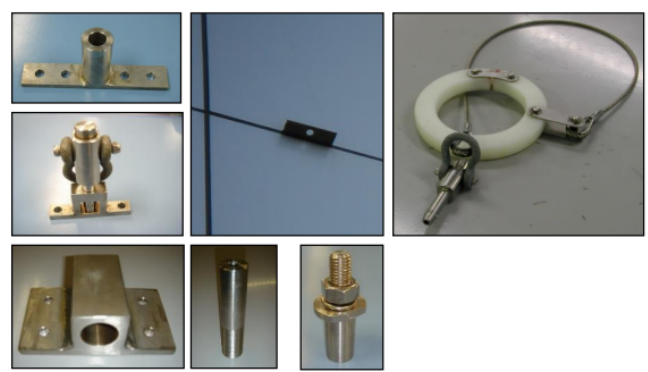

Fig. 8. Restraint Socket (male and female)

\subsection{Building Cleaning Cycle}

Time The cleaning cycle of the Bidex lot VII building is expected to be no more than 3 months in one cleaning period, this is what the building owner wants to keep it clean so that residents feel comfortable living in the Bidex lot VII building. The calculation of this cleaning time is taken on an average agreed by various consultants a maximum of $250 \mathrm{~m} 2$ per day. From this basis, the calculation of the cleaning time can be calculated as follows: If the total area for the facade being treated is $\pm 21,600$ square meters. While the area that is planned to be reached by the gondola is all sides of the building including the façade fin area that protrudes between 500-1000 $\mathrm{mm}$ so that it uses a special or unusual gondola system, namely the elbow jib type with butterfly jib cradle with estimate time:

a. Cleaning time per day $=$ facade area $/ 250 \mathrm{~m} 2$

b. Total cleaning time $=22,400 / 250=1$ cycle cleaning time $=89.6=90$ days 
c. 90 days / 25 working days in 1 month $=3.6$ months the gondola returns to its starting position.

d. So that what is expected in the design of the gondola at the Bidex lot VII building is fulfilled (it took less than 6 months to return to the initial cleaning position).

\section{Conclusion}

In the gondola design carried out at the Bidex Lot VII building, several conclusions were obtained, namely:

1. Obtained the most suitable model according to the needs of architect planning, civil structure, mechanical electrical, facade is an elbow model with butterfly jib cradle system

2. From the simulation results using AutoCAD images that all areas that want to be cleaned (facade) as a whole can be cleaned properly and there are no areas that are not reached by the gondola

3. Standard EN 1808 is used as a guide in security requirements on suspended access Devices (gondola), design calculations, stability criteria, construction - testing

4. The safety of the gondola operation is determined using a restraint socket with a soft rope system installed in the facade area

\section{References}

[1] BSI Standards Publication, BS EN 1808:2015 Safety requirements for suspended access equipment - Design calculation, Stability criteria, Construction - Examinations and Tests

[2] Sigmatech, PT; 2019 Technical Specifications for Bidex Lot VII Building Tender Documents, Jakarta

[3] WTP, PT; 2019 Contracts and BQ Tender Documents for Bidex Lot VII Building, Jakarta

[4] Ng, Kwok Wah (Regional Product Manager MHE Demag); 2020, BMU Interview (Gondola), Singapore 